\title{
Thickness Study of Er-Doped Magnesium Zinc Oxide Diode by Spray Pyrolysis
}

\author{
Yu-Ting Hsu ${ }^{1}$, Che-Chi Lee ${ }^{2}$, Wen-How Lan ${ }^{2, *}$, Kai-Feng Huang ${ }^{1}$, Kuo-Jen Chang ${ }^{3}$, \\ Jia-Ching Lin ${ }^{3}$, Shao-Yi Lee ${ }^{3}$, Wen-Jen Lin ${ }^{3}$, Mu-Chun Wang ${ }^{4}$ (D) and Chien-Jung Huang 5 \\ 1 Department of Electrophysics, National Chiao Tung University, Hsinchu 30010, Taiwan; \\ aliceythsu@gmail.com (Y.-T.H.); kfhuang@cc.nctu.edu.tw (K.-F.H.) \\ 2 Department of Electrical Engineering, National University of Kaohsiung, Kaohsiung 81148, Taiwan; \\ s8266397@gmail.com \\ 3 National Chung-Shan Institute of Science \& Technology, Taoyuan 32599, Taiwan; \\ mike.ckj@gmail.com (K.-J.C.); blackgodlin@gmail.com (J.-C.L.); tarry334@hotmail.com (S.-Y.L.); \\ wen.jenlin@msa.hinet.net (W.-J.L.) \\ 4 Department of Electronic Engineering, Minghsin University of Science and Technology, \\ Hsinchu 30401, Taiwan; mucwang@must.edu.tw \\ 5 Department of Applied Physics, National University of Kaohsiung, Kaohsiung 81148, Taiwan; \\ chien@nuk.edu.tw \\ * Correspondence: whlan@nuk.edu.tw
}

Received: 12 October 2018; Accepted: 4 December 2018; Published: 6 December 2018

\begin{abstract}
Erbium-doped magnesium zinc oxides were prepared through spray pyrolysis deposition at $450{ }^{\circ} \mathrm{C}$ with an aqueous solution containing magnesium nitrate, zinc acetate, erbium acetate, and indium nitrate precursors. Diodes with different erbium-doped magnesium zinc oxide thicknesses were fabricated. The effect of erbium-doped magnesium zinc oxide was investigated. The crystalline structure and surface morphology were analyzed using X-ray diffraction and scanning electron microscopy. The films exhibited a zinc oxide structure, with (002), (101), and (102) planes and tiny rods in a mixed hexagonal flakes surface morphology. With the photoluminescence analyses, defect states were identified. The diodes were fabricated via a metallization process in which the top contact was Au and the bottom contact was In. The current-voltage characteristics of these diodes were characterized. The structure resistance increased with the increase in erbium-doped magnesium zinc oxide thickness. With a reverse bias in excess of $8 \mathrm{~V}$, the light spectrum, with two distinct green light emissions at wavelengths of $532 \mathrm{~nm}$ and $553 \mathrm{~nm}$, was observed. The light intensity that resulted when using a different operation current of the diodes was investigated. The diode with an erbium-doped magnesium zinc oxide thickness of $230 \mathrm{~nm}$ shows high light intensity with an operational current of $80 \mathrm{~mA}$. The emission spectrum with different injection currents for the diodes was characterized and the mechanism is discussed.
\end{abstract}

Keywords: thickness; magnesium zinc oxide; erbium; diode

\section{Introduction}

Rare-earth-doped materials have been widely investigated in many applications in past decades [1-5]. Erbium (Er), one of the rare earth materials, has shown good performance in optoelectronic devices [6-8]. On the other hand, the wide bandgap II-VI semiconductor zinc oxide $(\mathrm{ZnO})$, which has a large exciton binding energy, is one of the most promising host materials in optoelectronic devices [8]. In a combination of the two materials, an Er-doped ZnO diode has shown Er-related green light luminescence performance [9]. However, a high reverse-biased operation is needed for the diode operation, which limits the device's applications. Still, the luminescence spectrum 
of such a diode is in the green gap spectral range for developing InGaN diodes [10]. Moreover, the emission wavelength is also in the low transmission loss window of PMMA-core optical fiber [11]. This is promising for the development of similar diodes as the emission source in Si-based photonic applications [12].

In the operation of the Er-doped $\mathrm{ZnO}$ diode, an operational voltage in excess of the reverse bias breakdown condition is needed to achieve the carrier impact ionization condition to transfer the energy to Er-related emissions [9]. When considering the quality of host material, the low defect requirement is an important issue in the breakdown behavior $[13,14]$. In the $\mathrm{ZnO}$ host material, certain defects such as zinc interstitial $\left(\mathrm{Zn}_{\mathrm{i}}\right)$ and oxygen vacancy $\left(\mathrm{V}_{\mathrm{O}}\right)$ are generally incorporated into the film. To improve this, it was found that some defect emissions in photoluminescence (PL) in $\mathrm{ZnO}$ can be reduced with the introduction of $\mathrm{Mg}$ [15]. The $\mathrm{MgZnO}$ device with suitable $\mathrm{Mg}$ content shows low dark current performance [16].

In ZnO-based material fabrication, many technologies can be applied [17-19]. The spray pyrolysis method is one of the best non-vacuum methods for $\mathrm{ZnO}$ deposition [20,21]. We investigated the diode performance of the $\mathrm{ZnO}: \mathrm{Er}$ on a p-Si substrate by spray pyrolysis method in the previous study [22]. In this study, a diode with different $\mathrm{MgZnO}$ :Er active layer thickness was prepared on a Si substrate by the spray pyrolysis method. The film morphology, crystalline quality, and diode properties were investigated. The effect of the injection current on diode electroluminescence intensity and spectral properties was studied.

\section{Experimental}

A MgZnO:Er layer followed by a ZnO:In layer were deposited on a p-type silicon substrate ((111), $5 \times 10^{18} \mathrm{~cm}^{-3}$ ) by the spray pyrolysis method at $450{ }^{\circ} \mathrm{C}$. Two aqueous solutions were prepared in the fabrication of $\mathrm{MgZnO}: \mathrm{Er}$ and $\mathrm{ZnO}: I n$ layers. In the fabrication of the $\mathrm{MgZnO}: \mathrm{Er}$ film, an aqueous solution mixed with $0.2 \mathrm{~mol} / \mathrm{L}$ zinc acetate dihydrate $\left(\mathrm{Zn}\left(\mathrm{CH}_{3} \mathrm{COOH}\right)_{2} \cdot 2 \mathrm{H}_{2} \mathrm{O}, \mathrm{ZnAc}\right)$, magnesium acetate tetrahydrate $\left(\mathrm{Mg}\left(\mathrm{CH}_{3} \mathrm{COOH}\right)_{2} \cdot 4 \mathrm{H}_{2} \mathrm{O}, \mathrm{MgAc}\right)(\mathrm{Mg} / \mathrm{Zn}=25$ at \%), and erbium acetate hydrate $\left(\mathrm{Er}\left(\mathrm{CH}_{3} \mathrm{COO}\right)_{3} \cdot 4 \mathrm{H}_{2} \mathrm{O}, \mathrm{ErAc}\right)(\mathrm{Er} / \mathrm{Zn}=5$ at \%) was prepared. In the fabrication of the $\mathrm{ZnO}$ :In film, an aqueous solution with $0.2 \mathrm{~mol} / \mathrm{L} \mathrm{ZnAc}$, mixed with indium nitrate hydrate $\left(\operatorname{In}\left(\mathrm{NO}_{3}\right)_{3} \cdot 5 \mathrm{H}_{2} \mathrm{O}, \mathrm{InNt}\right)$ ( $\mathrm{In} / \mathrm{Zn}=5$ at \%), was prepared. Before deposition, the aqueous solution was stirred for $1 \mathrm{~h}$ at room temperature to yield a clear solution. The $2 \times 1 \mathrm{~cm}$ Si substrate, cut from the Si wafer, was cleaned with acetone, rinsed in DI water, dried by $\mathrm{N}_{2}$ gas, dipped in diluted HF (1:20), rinsed in DI water and dried by $\mathrm{N}_{2}$ gas. After that, the Si substrate was transferred to a deposition chamber. After a high-temperature stabilization step, the substrate temperature was fixed at $450{ }^{\circ} \mathrm{C}$ and the $\mathrm{MgZnO}: \mathrm{Er}$ and $\mathrm{ZnO}:$ In layers were deposited sequentially. After the film deposition, In was deposited on the $\mathrm{Si}$ side by a thermal process. The front Au circular pad $(0.8 \mathrm{~mm}$ diameter) was formed by a direct-current magnetron sputtering process with a shadow mask. The thickness of the MgZnO:Er/ZnO:In layer was $170 \mathrm{~nm} / 100 \mathrm{~nm}, 230 \mathrm{~nm} / 100 \mathrm{~nm}$, and $550 \mathrm{~nm} / 100 \mathrm{~nm}$ for samples ST1, ST2, and ST3, respectively. The films' thickness was controlled with different deposition times after the thickness calibration runs. When considering the run-to-run deposition rate stability and thickness uniformity on the wafer, the thickness variation in the following device study was $\pm 11 \%$.

The surface morphology and cross-section of the samples were examined by scanning electron microscopy (SEM, Hitachi S-4300N, Tokyo, Japan). The element contents of the film were accomplished by XPS analysis (ESCALAB XI ${ }^{+}$, Thermo Fisher Scientific, Madison, WI, USA). The photoluminescence (PL) spectrum was obtained by an optical system with a spectrometer (HR2000+, Ocean Optics, Largo, FL, USA), He-Cd laser (325 nm wavelength), and a cryostat. The diode current-voltage and electroluminescence characters were examined by the spectrometer and source meter (Keithley 2400, Solon, $\mathrm{OH}, \mathrm{USA})$. 


\section{Results and Discussion}

Figure 1 exhibits the surface morphology of samples ST1, ST2, and ST3. The cross-section of each sample is shown in the inset. The morphology, with different sized hexagonal flakes and tiny rods, can be observed. For ST1, a small-grained structure can be observed in the cross-section. With an increase in the $\mathrm{MgZnO}:$ Er deposition time, a similar surface morphology can be observed. However, some large grains in the cross-section in ST3 can be observed, while small grains formed near the Si/MgZnO:Er interface. The varied morphology may originate from the deposition nature $[20,21]$ and deposition parameters [23] in the spray pyrolysis process.

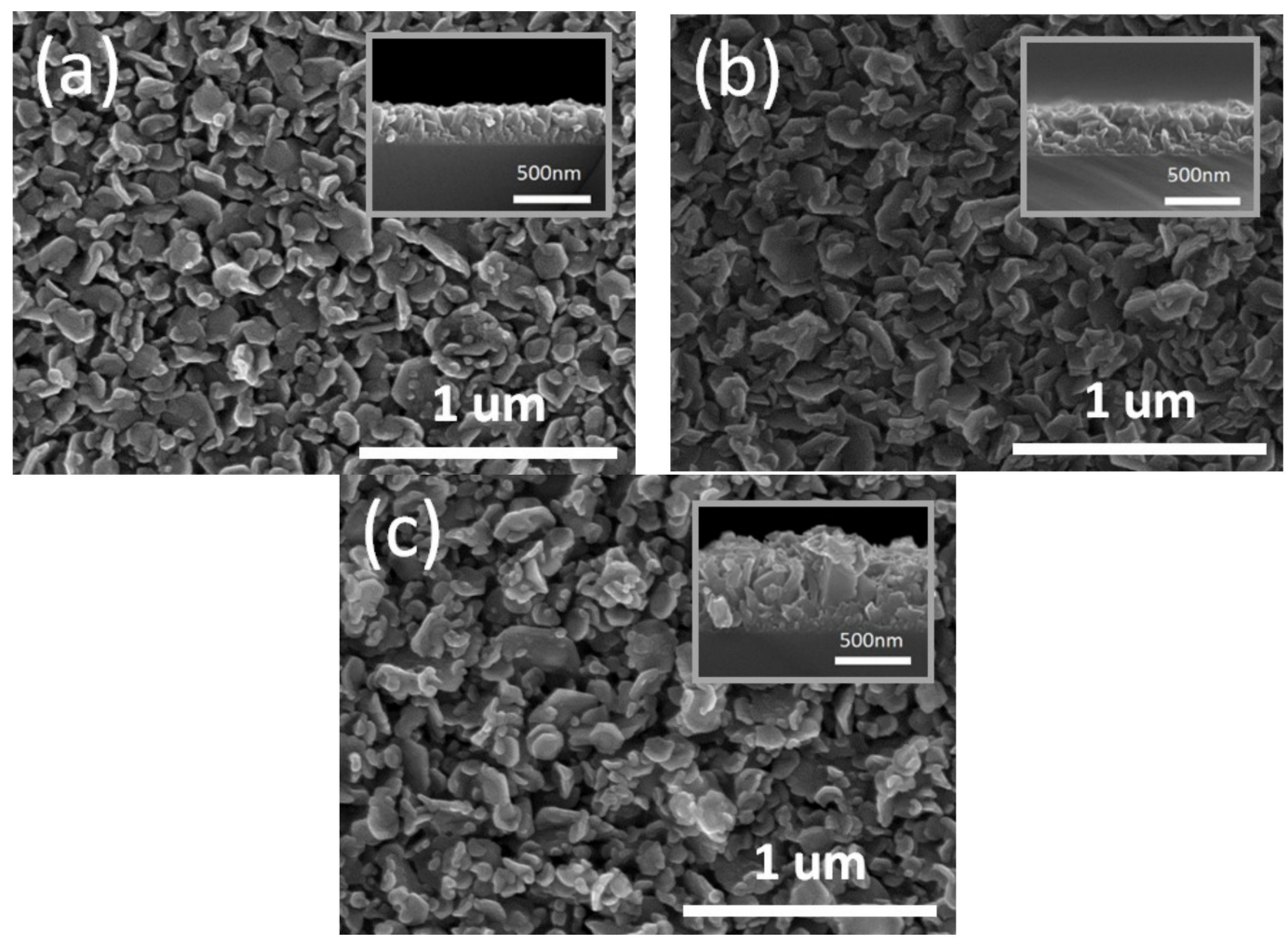

Figure 1. SEM images of the sample surface (a) ST1; (b) ST2; and (c) ST3. The cross-section is shown in the inset.

The XRD patterns of samples ST1, ST2, and ST3 are shown in Figure 2. Three crystalline orientations, (002), (101), and (102), of the $\mathrm{ZnO}$ wurtzite structure were observed. For $\mathrm{Mg}_{\mathrm{x}} \mathrm{Zn}_{1-\mathrm{x}} \mathrm{O}$, the $\mathrm{MgO}$ characteristic peak can be observed as phase separation occurred $(x \geq 0.4)$ [24]. For Er-doped $\mathrm{ZnO}$, there is generally no Er2O3 characteristic peak that can be observed while the doping content is low [25]. As the Mg composition and $\mathrm{Er}$ content in the $\mathrm{MgZnO}: \mathrm{Er}$ is low, there are no obvious MgO- [26] and $\mathrm{Er}_{2} \mathrm{O}_{3}$ [27]-related signals that can be observed. Regarding the peaks in Figure 2, the broad character is caused by the grain size effect [28] and the superposition of the two host materials, $\mathrm{MgZnO}$ and $\mathrm{ZnO}$ [29].

Figure 3a shows the PL spectrum of these samples measured at $10 \mathrm{~K}$. Two peaks with wavelengths of $362.7 \mathrm{~nm}(3.42 \mathrm{eV})$ and $366.5 \mathrm{~nm}(3.38 \mathrm{eV})$ can be observed for all samples. The two emission peaks come from the $\mathrm{MgZnO}$ :Er layer, mainly as both emissions display a higher energy than the band gap emission of $\mathrm{ZnO}$. Furthermore, as the energy difference for the two peaks is $40 \mathrm{meV}$, the near-band-edge (NBE) emission at $362.7 \mathrm{~nm}$ is attributed to the recombination of excitons bound to the neutral donor $\left(\mathrm{D}^{\circ} \mathrm{X}\right)$ and the emission at $366.5 \mathrm{~nm}$ is attributed to the two electron satellite (denoted as TES) transitions of the $D^{\circ} X[30,31]$. With the optical band gap evaluated from NBE emission, the $x$ quantity in the $\mathrm{Mg}_{\mathrm{x}} \mathrm{Zn}_{1-\mathrm{x}} \mathrm{O}: \mathrm{Er}$ layer was estimated to be approximately 0.1 [32]. 


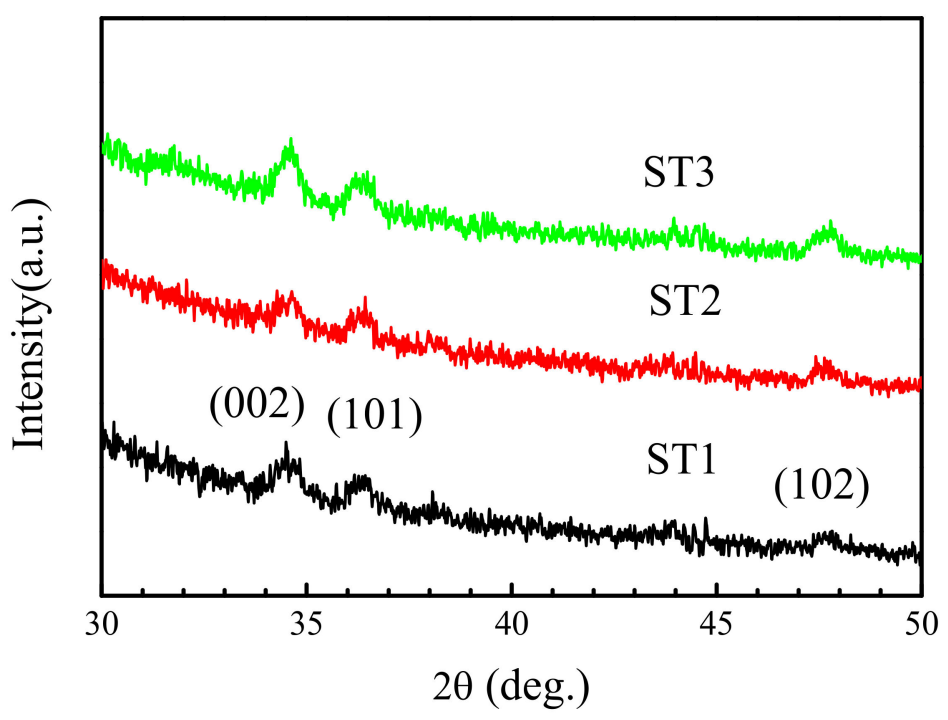

Figure 2. XRD patterns of samples ST1, ST2, and ST3.
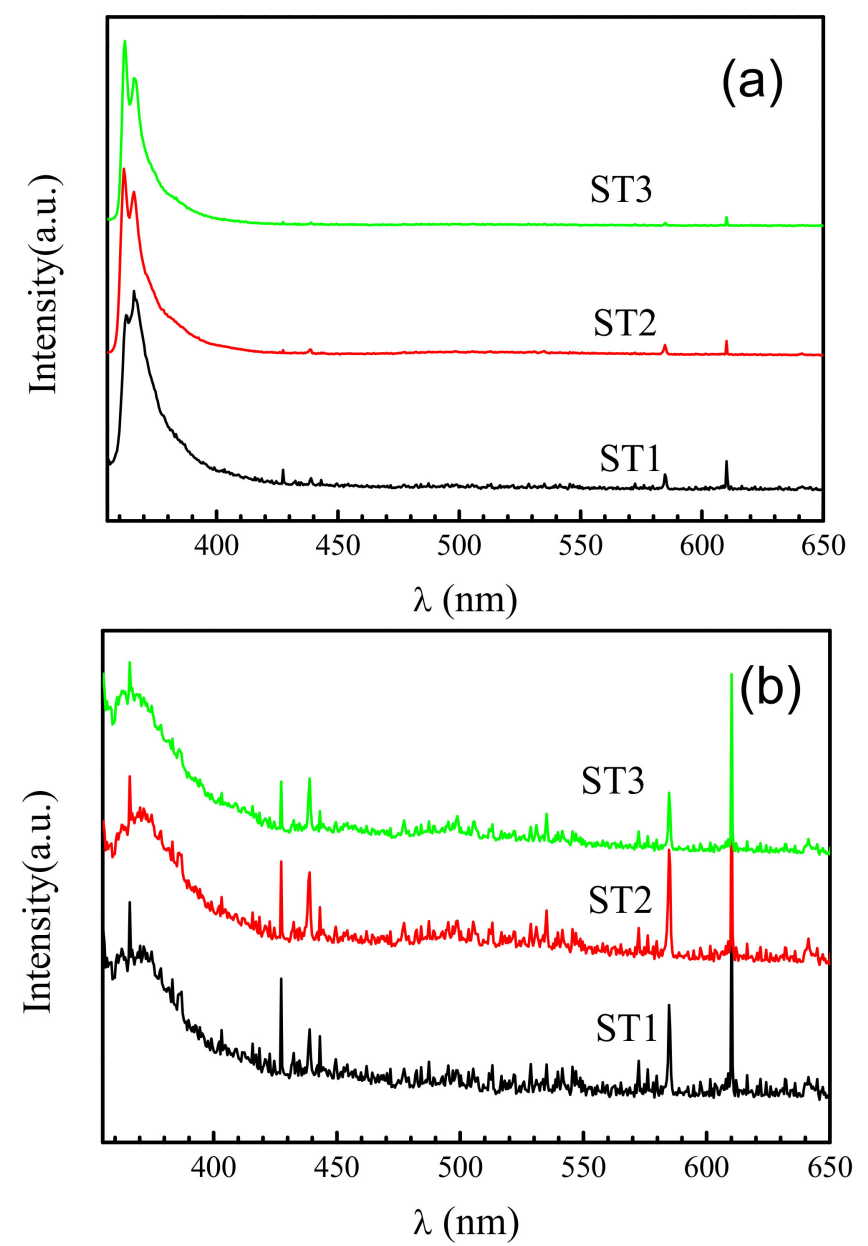

Figure 3. Photoluminescence spectra of samples ST1, ST2, and ST3 measured at (a) $10 \mathrm{~K}$ and (b) room temperature.

In the spectrum, a broad profile at a wavelength of $400 \mathrm{~nm}$ for all samples can be observed. The emission signal around $400 \mathrm{~nm}$ is attributed to the isolated $\mathrm{V}_{\mathrm{Zn}}$-related or $\mathrm{O}_{\mathrm{Zn}}$ type [33]. Certain such defects exist in the diode. Moreover, no obvious emissions around a wavelength of 480-520 nm [33,34] can be observed in the $10 \mathrm{~K}$ PL for all samples. 
Figure $3 \mathrm{~b}$ shows the PL spectrum of the samples measured at room temperature. Compared to the spectrum measured at $10 \mathrm{~K}$, a NBE band with temperature broadening [30] and band gap narrowing $[35,36]$ with a central wavelength at $368 \mathrm{~nm}$ was observed. A weak and broad blue emission (BE) around a wavelength of $500 \mathrm{~nm}$ can also be observed. The BE band was attributed to the carrier recombination between the extended zinc interstitial state and holes [37]. In PL measurement, the carriers were generated by a photo-exciting process and transported spatially. The emission was observed after the carrier recombination. The carrier spatial transport ability depends on the environmental temperature $[38,39]$. The inconsistency of the BE band for samples measured at $10 \mathrm{~K}$ and room temperature suggests the non-uniformed BE-related defect distribution in the samples. Furthermore, when we compare the PL spectra to those of the reported $\mathrm{ZnO}$ :Er diodes [9], the low $\mathrm{BE}$ band to $\mathrm{NBE}$ band intensity ratio $\left(\mathrm{I}_{\mathrm{BE}} / \mathrm{I}_{\mathrm{NBE}}\right)$ in our $\mathrm{MgZnO}$ :Er diode can be observed. A smaller BE-related defect may exist in our sample. This suggests the benefit of using $\mathrm{MgZnO}$ as the Er-doped layer.

For the Er-doped $\mathrm{ZnO}$, no Er-related emission in the PL measurement can be observed generally. The Er-related PL band for the ZnO-based materials can be observed for the sample prepared after a high-temperature procedure [40-42]. The oxygen vacancy states may make a contribution to the PL emissions [42].

When discussing why there were no Er-related PL emissions in the ZnO host, Iwan et al. [9] suggest that the intra-atomic level transition of the Er ion saturates at a much lower excitation photon power compared to the band to band transition of the host material. Harako et al. [43] point out that the observed visible band electroluminescence (EL) of the $\mathrm{ZnO}$ :Er diode was attributed to the carrier causing impact excitations of Er ions rather than to the energy transformation from e-h pairs in the $\mathrm{ZnO}$ host. Thus, the energy transform yield from e-h pairs, as generated by the PL process, to Er ion states in the visible band may be quite low, which might account for the missing Er-related emissions in the visible band.

Figure 4 exhibits the XPS spectra of $\mathrm{Zn} 2 \mathrm{p}, \mathrm{Mg}$ 1s, O 1s, and Er 4d in the MgZnO:Er layer of sample ST3. In Figure $4 a$, the $\mathrm{Zn} 2 \mathrm{p}_{3 / 2}$ signal with a peak energy of $1022 \mathrm{eV}$ can be observed. The value is within the reported range for high-temperature annealed $\mathrm{ZnO}$ [44]. A distorted profile toward the high-energy side of Figure $4 \mathrm{a}$ can be observed. This is ascribed to $\mathrm{Zn}^{2+}$ in hydroxide [45], and originates in the spray pyrolysis process. In Figure $4 \mathrm{~b}$, the binding energy, $1304 \mathrm{eV}$, of the $\mathrm{Mg} 1 \mathrm{~s}$ core level is observed [46]. In Figure 4c, the O1s signal with a peak energy of $531 \mathrm{eV}$ was observed. This value is near the reported $\mathrm{O}^{2-}$ on a normal wurtzite $\mathrm{ZnO}$ crystal $(530.8 \mathrm{eV})[44,47]$. The distorted shape in the high-energy side shows $\mathrm{O}^{2-}$ in hydroxide [48]. Figure $4 \mathrm{~d}$ shows the $\mathrm{Er} 4 \mathrm{~d}_{5 / 2}$ signal. This broad profile may include the signal related to Er-OH bonds (peak energy at $170.4 \mathrm{eV}$ ) and the signal related to Er-O bonds (peak energy at $168.4 \mathrm{eV}$ ) [46]. The $\mathrm{Er} / \mathrm{Zn}$ ratio in the film is estimated be $0.2 \%$ from the XPS characterization. As the atomic ratio of $\mathrm{Er} / \mathrm{Zn}$ is $5 \%$ in the precursor, the incorporation efficiency of $\mathrm{Er}$ from ErAc is low compared to that of $\mathrm{Zn}$ from $\mathrm{ZnAc}$ in the spray pyrolysis deposition process.

Figure 5 shows the current-voltage (I-V) characteristics of diodes ST1, ST2, and ST3, measured at room temperature. The error bars show the variations of the five diodes in each sample. A rectification character in forward bias and breakdown behavior in reverse bias can be observed. In the reverse bias region, the breakdown voltage increases with the increase in the MgZnO:Er layer's thickness. As with the higher bandgap host material $\mathrm{MgZnO}$, the samples show a small reverse bias current around $-4 \mathrm{~V}$ compared to the reported $\mathrm{ZnO}:$ Er diodes [22]. On the other hand, the diode and series resistance $\left(\mathrm{R}_{\mathrm{s}}\right)$ and ideality factor (n) that describe the diode can be extracted [48] and are listed in Table 1. 

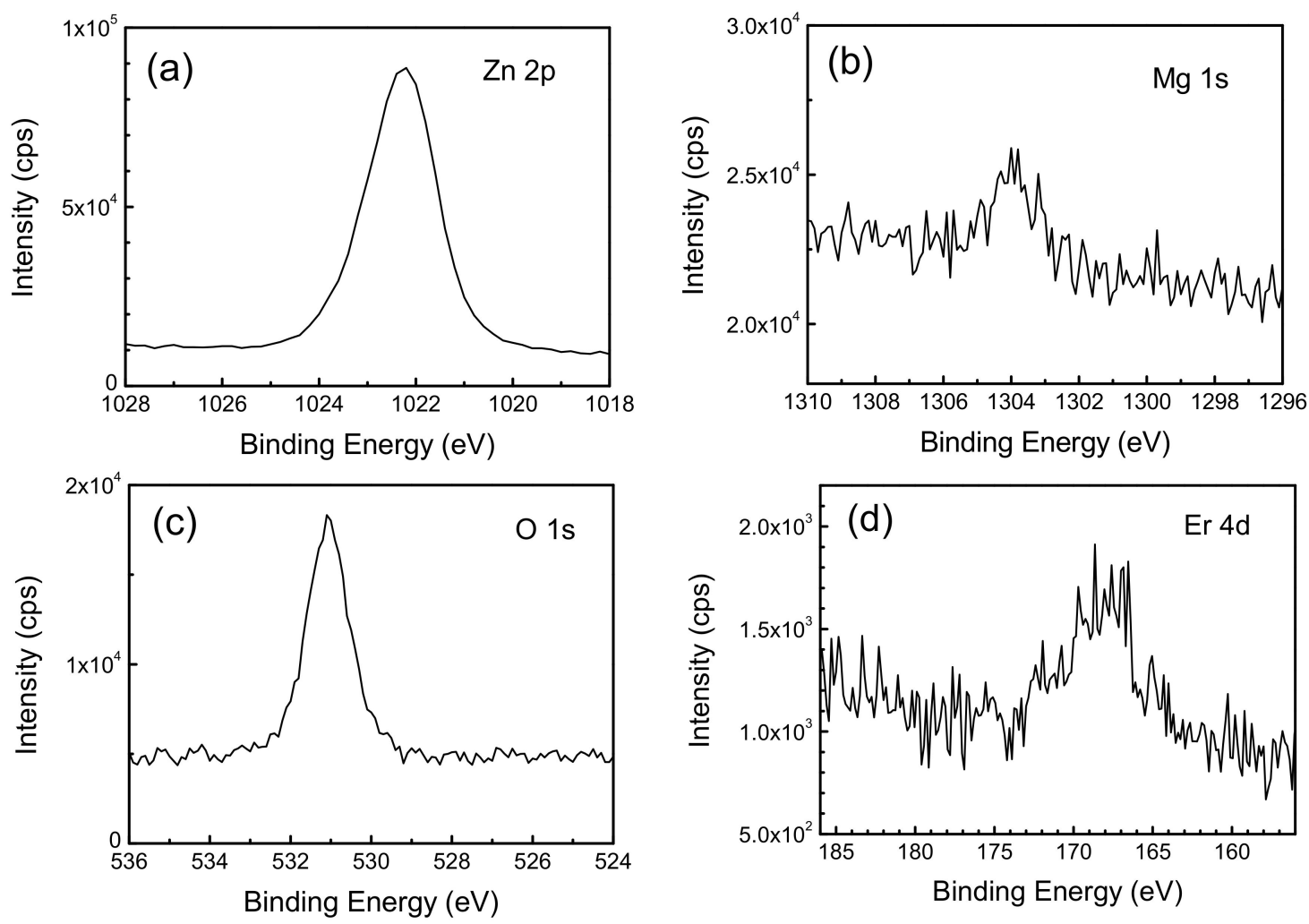

Figure 4. XPS spectra of (a) Zn 2p; (b) Mg 1s; (c) O 1s; and (d) Er 4d in the MgZnO:Er layer of sample ST3.

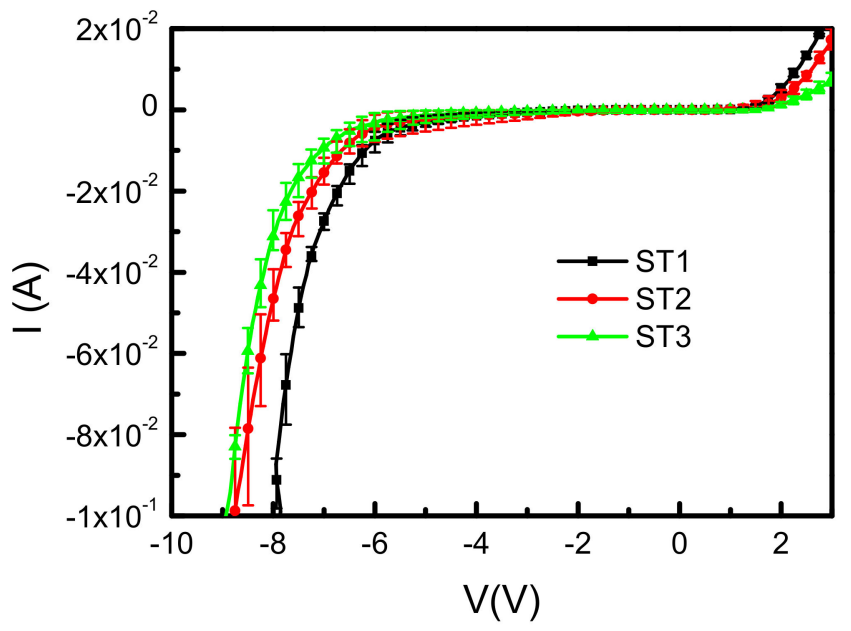

Figure 5. Current-voltage (I-V) characteristics of samples ST1, ST2, and ST3 measured at room temperature.

Table 1. The diode ideality factor (n) and series resistance (Rs) of the p-Si/MgZnO:Er/ZnO:In diodes.

\begin{tabular}{ccc}
\hline Sample & $\mathbf{n}$ & Rs $(\boldsymbol{\Omega})$ \\
\hline ST1 & $6.4 \pm 0.9$ & $38 \pm 8$ \\
ST2 & $6.1 \pm 0.8$ & $33 \pm 6$ \\
ST3 & $7.2 \pm 0.6$ & $107 \pm 6$ \\
\hline
\end{tabular}

In Table 1 , the quantities and variations of diode ideality $\mathrm{n}$ for considering five diodes on each sample were listed. Since $\mathrm{n}$ is 1 for the recombination of injected carriers in the neutral region, it is 2 for the carrier recombination by mediated recombination centers in the space charge region $[49,50]$. A high ideality factor with $\mathrm{n}$ greater than 2 can be observed in many diodes made from wide bandgap 
materials [51]. For the heterostructured diode with grained morphology in this work, the high ideality may arise from the effect of the heterojunction [52] and/or the high defect density [9] around the grain boundary in the $\mathrm{MgZnO}$ :Er layer. In Table 1, the high series resistance quantity for ST3 can be observed. For a film with a large grain, the boundary induced conduction is inhibited. Thus the high $R_{s}$ from ST3 may come from the large grain as shown in Figure 1 and/or from the thick $\mathrm{MgZnO}: \mathrm{Er}$ layer.

Figure 6 shows the electroluminescence spectra of ST1, ST2, and ST3 with different reverse biased injected current measured at room temperature. Figure 7 expresses the light intensity-injection current (L-I) characteristics of samples ST1, ST2, and ST3 measured at room temperature. The error bar for each measurement is shown. For the diode under high reverse bias, the electrons and holes, which were created and accelerated in the depletion region due to the high electric field, transfer the energy to excite Er ions by impact ionization $[9,53,54]$ and cause the emissions of the diode. In Figure 4, two emission bands in the visible range related to the energy state transitions of $\mathrm{Er}^{3+}$ of ${ }^{2} \mathrm{H}_{11 / 2} \rightarrow{ }^{4} \mathrm{I}_{15 / 2}$ (around $532 \mathrm{~nm}$ ) and ${ }^{4} \mathrm{~S}_{3 / 2} \rightarrow{ }^{4} \mathrm{I}_{15 / 2}$ (around $553 \mathrm{~nm}$ ) [55] can be observed. Compared to the reported emission spectra in the $\mathrm{ZnO}: \mathrm{Er}$ diode [22], little spectral difference can be observed in the MgZnO:Er samples. The fine spectrum variation in the emission band is caused by the variation of the host structure [56].
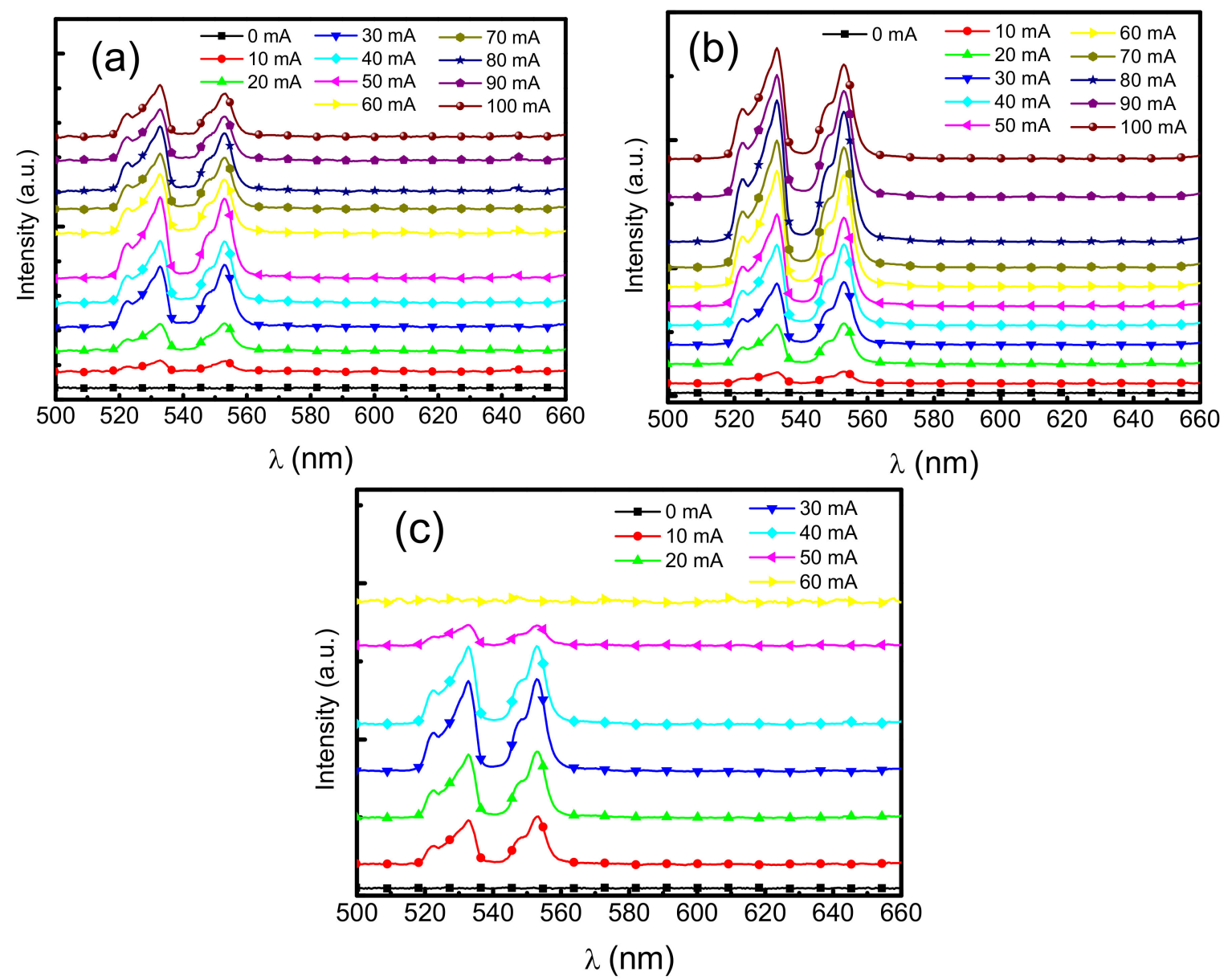

Figure 6. The electroluminescence spectra of samples (a) ST1; (b) ST2; and (c) ST3 measured at room temperature with different injection currents measured at room temperature. 


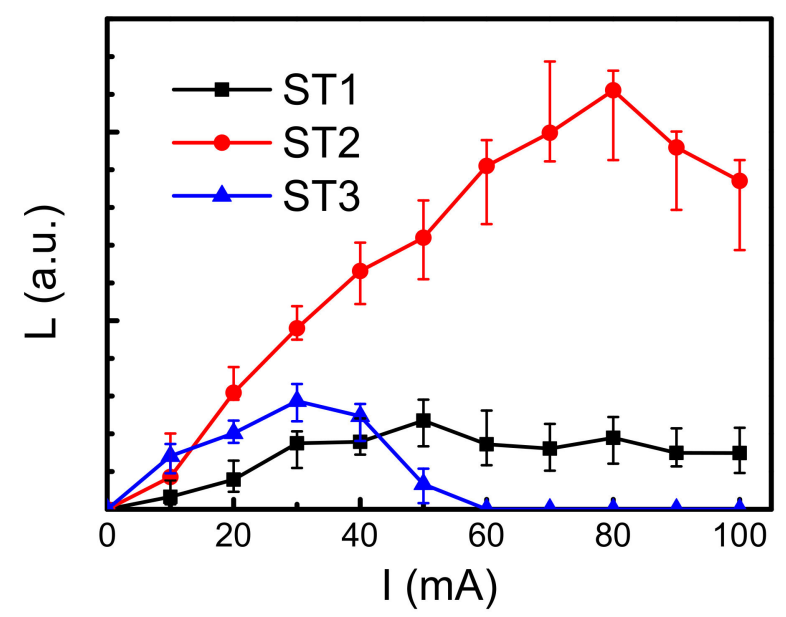

Figure 7. The light intensity-current (L-I) characteristics of samples ST1, ST2, and ST3 measured at room temperature.

In terms of the L-I character of ST1, the light intensity shows an increasing-remaining behavior with the increase in the injection current. The low light intensity of ST1 may originate from the thin MgZnO:Er active layer. For sample ST2, the light intensity increases with the increase in the injection current. The light intensity then begins to decrease when the injection current is in excess of $80 \mathrm{~mA}$. The decreasing character originates from the joule heat generated under a high injection current $[57,58]$. For ST3 under operation, as the diode preserved a thick MgZnO:Er layer and a high overall series resistance, the joule heat accumulated heavily in the active region and thus caused damage to the diode with an injection current in excess of $60 \mathrm{~mA}$.

Figure 8 shows the electroluminescence intensity ratio between the ${ }^{2} \mathrm{H}_{11 / 2} \rightarrow{ }^{4} \mathrm{I}_{15 / 2}$ transition $\left(\mathrm{I}_{532 \mathrm{~nm}}\right)$ and the ${ }^{4} \mathrm{~S}_{3 / 2} \rightarrow{ }^{4} \mathrm{I}_{15 / 2}\left(\mathrm{I}_{553} \mathrm{~nm}\right)$ transition of the samples with different operational currents. The intensity ratio $R\left(I_{532} \mathrm{~nm} / \mathrm{I}_{553} \mathrm{~nm}\right)$ increases with the increase in the injection current. For the diode operating in an avalanche breakdown condition, the increased current was caused by the enhanced impact ionization due to the high reverse bias. The carriers preserved high impact energy in the case of a high injection current. The increase in the short wavelength emission intensity in ${ }^{2} \mathrm{H}_{11 / 2}$ is due to the increase of high energy carrier impaction. This causes an increase in the intensity ratio $\mathrm{R}\left(\mathrm{I}_{532 \mathrm{~nm}} / \mathrm{I}_{553} \mathrm{~nm}\right)$ with the increase in the injection current.

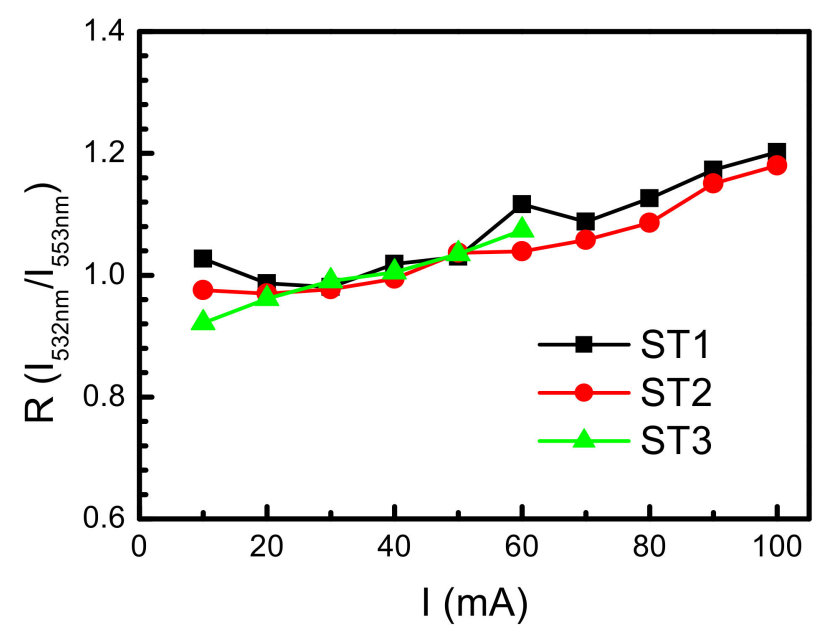

Figure 8. The electroluminescence intensity ratio $R\left(\mathrm{I}_{532} \mathrm{~nm} / \mathrm{I}_{553} \mathrm{~nm}\right)$ of samples ST1, ST2, and ST3 measured at room temperature with different injection current $\mathrm{I}$. 


\section{Conclusions}

Heterostructured p-Si/MgZnO:Er/ZnO:In diodes with different $\mathrm{MgZnO}: \mathrm{Er}$ active layer thicknesses were prepared by spray pyrolysis. The morphologies, crystalline properties, and diode characteristics were investigated. The surface morphology varied with the increase in film thickness. The diode series resistance increases with the increase in the MgZnO:Er layer. Two Er ions' related green emissions were characterized. The emission intensity increased with the increase in the $\mathrm{MgZnO}: \mathrm{Er}$ layer at a low injection current. With a thick MgZnO:Er layer operating at a high injection current, the diode represented worse emissions due to the high resistance. With the increase in the injection current, green emissions with a short wavelength had the advantage. The possible mechanisms were discussed.

Author Contributions: Individual contributions to this research. Conceptualization: Y.-T.H., W.-H.L. and K.-F.H., Methodology: Y.-T.H., C.-C.L., S.-Y.L., Validation: K.-J.C., J.-C.L., S.-Y.L., W.-J.L., Formal Analysis: W.-H.L., Investigation: W.-H.L., Data Curation: W.-H.L. and Y.-T.H., Writing-Original Draft Preparation: W.-H.L., M.-C.W. and C.-J.H., Writing—Review \& Editing: W.-H.L., Visualization: W.-H.L.

Funding: This research was funded by the Ministry of Science and Technology, Taiwan (MOST 106-2221-E-390-012-, MOST 107-2221-E-390-013-), and National Chung Shan Institute of Science and Technology, R.O.C., NCSIST-104-V404(107).

Conflicts of Interest: The authors declare no conflict of interest.

\section{References}

1. Gapontsev, V.P.; Matitsin, S.M.; Isineev, A.A.; Kravchenko, V.B. Erbium glass lasers and their applications. Opt. Laser Technol. 1982, 14, 189-196. [CrossRef]

2. Kamik, S.A.; Chandrappan, J.; Murray, M.; Steenson, P.; Krauss, T.F.; Jose, G. Ultrafast laser plasma doping of Er3+ ions in silica-on-silicon for optical waveguiding applications. Opt. Lett. 2016, 41, 4684-4687.

3. Irrera, A.; Miritello, M.; Pacifici, D.; Franzo, G.; Priolo, F.; Iacona, F.; Sanfilippo, D.; di Stefano, G.; Fallica, P.G. Electroluminescence properties of SiOx layers implanted with rare earth ions. Nucl. Instrum. Methods Phys. Res. B 2004, 216, 222-227. [CrossRef]

4. Nakamura, K.; Takemoto, S.; Terai, Y.; Suzuki, M.; Koizumi, A.; Takeda, Y.; Tonouchi, M.; Fujiwara, Y. Direct observation of trapping of photo-excited carriers in Er, O-codoped GaAs. Phys. B 2006, 376-377, 556-559. [CrossRef]

5. Fujiwara, Y.; Koizumi, A.; Urakami, A.; Yoshikane, T.; Inoue, K.; Takeda, Y. Room temperature $1.5 \mu \mathrm{m}$ electroluminescnence from GaInP/Er,O-codoped GaAs/GaInP double heterostructure injection-type light emitting diodes grown by organometallic vapor phase epitaxy. Mater. Sci. Eng. B 2003, 105, 57-60. [CrossRef]

6. Dahal, R.; Lin, J.Y.; Jiang, H.X.; Zavada, J.M. Room temperature $1.5 \mu \mathrm{m}$ electroluminescnence from $\mathrm{GaInP} / \mathrm{Er}, \mathrm{O}$-codoped GaAs/GaInP double heterostructure injection-type light emitting diodes grown by organometallic vapor phase epitaxy. Opt. Mater. 2011, 33, 1066-1070. [CrossRef]

7. Nyk, M.; Kuzmin, A.; Prasad, P.N.; Strek, W.; de Araújo, C. Red up-conversion emission from nanocrystalline GaN powders co-doped with Er3+ and Yb3+. Opt. Mater. 2009, 31, 800-804. [CrossRef]

8. Li, S.; Ye, S.; Liu, T.; Wang, H.; Wang, D. Enhanced up-conversion emissions in ZnO-LiYbO2: RE3+ (RE= Er or Ho) hybrid phosphors through surface modification. J. Alloy. Compd. 2016, 658, 85-90. [CrossRef]

9. Iwan, S.; Bambang, S.; Zhao, J.L.; Tan, S.T.; Fan, H.M.; Sun, L.; Zhang, S.; Ryu, H.H.; Sun, X.W. Green electroluminescence from an n-ZnO: Er/p-Si heterostructured light-emitting diode. Phys. B 2012, 407, 2721-2724. [CrossRef]

10. Saito, S.; Hashimoto, R.; Hwang, J.; Nunoue, S. InGaN Light-Emitting Diodes on c-Face Sapphire Substrates in Green Gap Spectral Range. Appl. Phys. Express 2003, 6, 111004. [CrossRef]

11. Zubia, J.; Arrue, J. Plastic Optical Fibers: An Introduction to Their Technological Processes and Applications. Opt. Fiber Technol. 2001, 7, 101-140. [CrossRef]

12. Jambois, O.; Berencen, Y.; Hijazi, K.; Wojdak, M.; Kenyon, A.J.; Gourbilleau, F.; Rizk, R.; Garrido, B. Current transport and electroluminesc ence mechanisms in thin $\mathrm{SiO}_{2}$ films containing $\mathrm{Si}$ nanocluster-sensitized erbium ions. J. Appl. Phys. 2009, 106, 063526. [CrossRef] 
13. Breitenstein, O.; Bauer, J.; Wagner, J.M.; Zakharov, N.; Blumtritt, H.; Lotnyk, A.; Kasemann, M.; Kwapil, W.; Warta, W. Defect-Induced Breakdown in Multicrystalline Silicon Solar Cells. IEEE Trans. Elec. Dev. 2010, 57, 2227-2234. [CrossRef]

14. Kizilyalli, I.C.; Edwards, A.P.; Nie, H.; Disney, D.; Bour, D. High Voltage Vertical GaN p-n Diodes with Avalanche Capability. IEEE Trans. Elec. Dev. 2013, 60, 3067-3070. [CrossRef]

15. Shan, F.K.; Kim, B.I.; Liu, G.X.; Liu, Z.F.; Sohn, J.Y.; Lee, W.J.; Shin, B.C.; Yu, Y.S. Blueshift of near band edge emission in $\mathrm{Mg}$ doped $\mathrm{ZnO}$ thin films and aging. J. Appl. Phys. 2004, 95, 4772-4776. [CrossRef]

16. Chi, C.T.; Cheng, I.C.; Chen, J.Z. Bandgap tuning of $\mathrm{MgZnO}$ in flexible transparent $\mathrm{n}+-\mathrm{ZnO}: \mathrm{Al}$ /n-MgZnO/p-CuAlOx:Ca diodes on polyethylene terephthalate substrates. J. Alloy. Compd. 2012, 544, 111-114. [CrossRef]

17. Perez-Casero, R.; Gutiérrez-Llorente, A.; Pons-Y-Moll, O.; Seiler, W.; Defourneau, R.M.; Millon, E.; Perriere, J.; Goldner, P.; Viana, B. Er-doped ZnO thin films grown by pulsed-laser deposition. J. Appl. Phys. 2005, 97, 054905. [CrossRef]

18. Lautenschlaeger, S.; Eisermann, S.; Meyer, B.K.; Callison, G.; Wagner, M.R.; Hoffmann, A. Nitrogen incorporation in homoepitaxial ZnO CVD epilayers. Phys. Status Solidi RRL 2009, 3, 16-18. [CrossRef]

19. Ogata, K.; Sakurai, K.; Fujita, S.; Matsushige, K. Effects of thermal annealing of ZnO layers grown by MBE. J. Cryst. Growth 2000, 214-215, 312-315. [CrossRef]

20. Inamdar, S.I.; Rajpure, K.Y. High-performance metal-semiconductor-metal UV photodetector based on spray deposited ZnO thin films. J. Alloy. Compd. 2014, 595, 55-59. [CrossRef]

21. Allah, F.K.; Abe, S.Y.; Nunez, C.M.; Khelil, A.; Cattin, L.; Morsli, M.; Bernede, J.C.; Bougrine, A.; del Valle, M.A.; Diaz, F.R. Characterisation of porous doped $\mathrm{ZnO}$ thin films deposited by spray pyrolysis technique. Appl. Surf. Sci. 2007, 253, 9241-9247. [CrossRef]

22. Lin, T.H.; Lan, W.H.; Shih, M.C.; Wang, M.C.; Chang, K.J.; Lin, J.C.; Lee, S.Y.; Lin, W.J.; Huang, C.J. Resistance Study of Er-doped Zinc Oxide Diode by Spray Pyrolysis. Sens. Mater. 2018, 30, 939-946.

23. Zhao, J.L.; Li, X.M.; Zhang, S.; Yang, C.; Gao, X.D.; Yu, W.D. Highly (002)-oriented ZnO film grown by ultrasonic spray pyrolysis on ZnO-seeded Si (100) substrate. J. Mater. Res. 2006, 21, 2185-2190. [CrossRef]

24. Morrison, J.L.; Huso, J.; Hoeck, H.; Casey, E.; Mitchell, J.; Bergman, L.; Norton, M.G. Optical properties of $\mathrm{ZnO}$ and $\mathrm{MgZnO}$ nanocrystals below and at the phase separation Range. J. Appl. Phys. 2008, 104, 123519. [CrossRef]

25. Jayachandraiah, C.; Krishnaiah, G. Erbium induced raman studies and dielectric properties of Er-doped ZnO nanoparticles. Adv. Mater. Lett. 2015, 6, 743-748. [CrossRef]

26. Shiau, J.S.; Brahma, S.; Liu, C.P.; Huang, J.L. Ultraviolet photodetectors based on MgZnO thin film grown by RF magnetron sputtering. Thin Solid Films 2016, 620, 170-174. [CrossRef]

27. Chen, F.H.; Her, J.L.; Shao, Y.H.; Matsuda, Y.H.; Pan, T.M. Structural and electrical characteristics of high-k Er2O3 and Er2TiO5 gate dielectrics for a-IGZO thin-film transistors. Nanoscale Res. Lett. 2013, 8, 1-5. [CrossRef]

28. Shelke, V.; Bhole, M.P.; Patil, D.S. Open air annealing effect on the electrical and optical properties of tin doped ZnO nanostructure. Solid State Sci. 2012, 14, 705-710. [CrossRef]

29. Wang, X.; Saito, K.; Tanaka, T.; Nishio, M.; Guo, Q. Lower temperature growth of single phase MgZnO films in all Mg content range. J. Alloy. Compd. 2015, 627, 383-387. [CrossRef]

30. Teke, A.; Ozgur, U.; Dogan, S.; Gu, X.; Morkoc, H.; Nemeth, B.; Nause, J.; Everitt, H.O. Excitonic fine structure and recombination dynamics in single-crystalline ZnO. Phys. Rev. B 2004, 70, 195207. [CrossRef]

31. Meyer, B.K.; Alves, H.; Hofmann, D.M.; Kriegseis, W.; Forster, D.; Bertram, F.; Christen, J.; Hoffmann, A.; Strabburg, M.; Dworzak, M.; et al. Bound exciton and donor-acceptor pair recombinations in ZnO. Phys. Stat. Sol. (B) 2004, 241, 231-260. [CrossRef]

32. Yan, W.; Tan, J.; Zhang, W.; Liang, Y.; Feng, S.; Lei, X.; Wang, H. Spray pyrolysis derived ZnMgO:In thin films: Investigation of the structural, optical and electrical properties. Superlattices Microstruct. 2013, 60, 407-413. [CrossRef]

33. Pal, S.; Rakshit, T.; Singha, S.S.; Asokan, K.; Dutta, S.; Jana, D.; Sarkar, A. Shallow acceptor state in ZnO realized by ion irradiation and annealing route. J. Alloy. Compd. 2017, 703, 26-33. [CrossRef]

34. RWahyuono, A.; Hermann-Westendorf, F.; Dellith, A.; Schmidt, C.; Dellith, J.; Plentz, J.; Schulz, M.; Presselt, M.; Seyring, M.; Rettenmeyer, M.; et al. Effect of annealing on the sub-bandgap, defects and trapping states of ZnO nanostructures. Chem. Phys. 2017, 483-484, 112-121. [CrossRef] 
35. Varshni, Y.P. Temperature Dependence of the Energy Gap in Semiconductor. Physica 1967, 34, $149-154$. [CrossRef]

36. Wang, L.; Giles, N.C. Temperature dependence of the free-exciton transition energy in zinc oxide by photoluminescence excitation spectroscopy. J. Appl. Phys. 2003, 94, 973-975. [CrossRef]

37. Zeng, H.; Duan, G.; Li, Y.; Yang, S.; Xu, X.; Cai, W. Blue luminescence of ZnO nanoparticles based on non-equilibrium processes: Defect origins and emission controls. Adv. Funct. Mater. 2010, 20, 561-572. [CrossRef]

38. Ellmer, K.; Mientus, R. Carrier transport in polycrystalline transparent conductive oxides: A comparative study of zinc oxide and indium oxide. Thin Solid Films 2008, 516, 4620-4627. [CrossRef]

39. Yu, C.C.; Lan, W.H.; Huang, K.F. Indium-nitrogen co-doped zinc oxide thin film deposited by ultrasonic spray pyrolysis on n-(111) Si substrate: The effect of film thickness. J. Nanomater. 2014, 2014, 861234. [CrossRef]

40. Elleuch, R.; Salhi, R.; Maalej, N.; Deschanvres, J.L.; Maalej, R. Structural and luminescence correlation of annealed Er-ZnO/Si thin films deposited by AACVD process. Mater. Sci. Eng. B 2013, 178, 1124-1129. [CrossRef]

41. Lee, C.; Chen, C.A.; Lai, C.Y.; Lin, W.J.; Chang, K.J.; Feng, D.J.Y.; Shih, M.C.; Wang, M.C.; Lan, W.H. Photoluminescence Study of Annealed MgZnO:Er Diode. In Proceedings of the Optics \& Photonics Taiwan, International Conference (OPTIC) 2018, Tainan, Taiwan, 6-8 December 2018.

42. Kumar, P.; Sharma, V.; Sarwa, A.; Kumar, A.; Surbhi; Goyal, R.; Sachdev, K.; Annapoorni, S.; Asokan, K.; Kanjilal, D. Understanding the origin of ferromagnetism in Erdoped ZnO system. RSC Adv. 2016, 6, 89242-89249. [CrossRef]

43. Harako, S.; Yokoyama, S.; Ide, K.; Zhao, X.; Komoro, S. Visible and infrared electroluminescence from an Er-doped n-ZnO/p-Si light emitting diode. Phys. Stat. Sol. (A) 2008, 205, 19-22. [CrossRef]

44. Wei, X.Q.; Man, B.Y.; Liu, M.; Xue, C.S.; Zhuang, H.Z.; Yang, C. Blue luminescent centers and microstructural evaluation by XPS and Raman in ZnO thin films annealed in vacuum, N2 and O2. Phys. B 2007, 388, 145-152. [CrossRef]

45. Wang, M.; Jiang, L.; Kim, E.J.; Hahn, S.H. Electronic structure and optical properties of Zn(OH)2: LDA+U calculations and intense yellow Luminescence. RSC Adv. 2015, 5, 87496-87503. [CrossRef]

46. Corneille, J.S.; He, J.W.; Goodmanm, D.W. XPS characterization of ultra-thin MgO films on a Mo(100) surface. Surf. Sci. 1994, 306, 269-278. [CrossRef]

47. Coppa, B.J.; Davis, R.F.; Nemanich, R.J. Gold Schottky contacts on oxygen plasma-treated, n-type ZnO(0001-). Appl. Phys. Lett. 2003, 82, 400-403. [CrossRef]

48. Fred Schubert, E. Light-Emitting Diodes, 2nd ed.; Cambridge University Press: New York, NY, USA, 2006; pp. 64-65.

49. Shah, J.M.; Li, Y.L.; Gessmann, T.; Schubert, E.F. Experimental analysis and theoretical model for anomalously high ideality factors $(\mathrm{n}>>2.0)$ in AlGaN/GaN pn junction diodes. J. Appl. Phys. 2003, 94, 2627-2629. [CrossRef]

50. Sah, C.T.; Noyce, R.N.; Shockley, W. Carrier generation and recombination in pn junctions and pn junction characteristics. Proc. IRE 1957, 45, 1228-1243. [CrossRef]

51. Zebbar, N.; Kheireddine, Y.; Mokeddem, K.; Hafdallah, A.; Kechouane, M.; Aida, M.S. Structural, optical and electrical properties of $\mathrm{n}-\mathrm{ZnO} / \mathrm{p}-\mathrm{Si}$ heterojunction prepared by ultrasonic spray. Mater. Sci. Semicond. Process. 2011, 14, 229-234. [CrossRef]

52. Zhu, D.; Xu, J.; Noemaun, A.N.; Kim, J.K.; Schubert, E.F.; Crawford, M.H.; Koleske, D.D. The origin of the high diode-ideality factors in GaInN/GaN multiple quantum well light-emitting diodes. Appl. Phys. Lett. 2009, 94, 081113. [CrossRef]

53. Langer, J.M.; Lemanska-Bajorek, A.; Suchocki, A. A method of excitation profiling in high-field electroluminescence. Appl. Phys. Lett. 1981, 39, 386-388. [CrossRef]

54. Franzo, G.; Coffa, S.; Priolo, F.; Spinella, C. Mechanism and performance of forward and reverse bias electroluminescence at $1.54 \mu \mathrm{m}$ from Er-doped Si diodes. J. Appl. Phys. 1997, 81, 2784-2793. [CrossRef]

55. Prucnal, S.; Rebohle, L.; Skorupa, W. Electroluminescence from Er and Yb co-doped silicon dioxide layers: The excitation mechanism. J. Non-Cryst. Solids 2011, 357, 915-918. [CrossRef]

56. Polman, A. Erbium as a probe of everything? Phys. B 2001, 300, 78-90. [CrossRef] 
57. Kim, H.; Yang, H.; Huh, C.; Kim, S.W.; Park, S.J.; Hwang, H. Electromigration-induced failure of GaN multi-quantum well light emitting diode. Electron. Lett. 2000, 36, 908-910. [CrossRef]

58. Figge, S.; Bottcher, T.; Hommel, D.; Zellweger, C.; Ilegems, M. Heat generation and dissipation in GaN-based light emitting devices. Phys. Stat. Sol. (A) 2003, 200, 83-86. [CrossRef]

(c) 2018 by the authors. Licensee MDPI, Basel, Switzerland. This article is an open access article distributed under the terms and conditions of the Creative Commons Attribution (CC BY) license (http:/ / creativecommons.org/licenses/by/4.0/). 